\title{
Erratum to: Propensity of Hyoscyamus Niger seeds methanolic extract to allay stereotaxically rotenone-induced Parkinson's disease symptoms in rats
}

Dharmendra Kumar Khatri ${ }^{1} \cdot$ Archana Ramesh Juvekar $^{1}$

Published online: 19 November 2015

(C) Institute of Korean Medicine, Kyung Hee University and Springer Science+Business Media Dordrecht 2015

Erratum to: Orient Pharm Exp Med

DOI 10.1007/s13596-015-0202-x

Unfortunately, Fig. $1 \mathrm{a}$ and $\mathrm{b}$ are missing in the original version of the article. The corrected Fig. 1 is shown in this erratum.

The online version of the original article can be found at http://dx.doi.org/ 10.1007/s13596-015-0202-x

$\triangle$ Archana Ramesh Juvekar juvekar.archana@gmail.com

1 Department of Pharmaceutical Sciences and Technology,Pharmacology Research Lab-II Institute of Chemical Technology, (University under Section 3 of UGC Act-1956, Elite Status and Centre of Excellence-Government of Maharashtra TEQIP Phase II, Funded), Mumbai, India 
Fig. 1 a HPLC chromatogram of standard L-dopa at $25 \mathrm{ppm}$ showed retention time $4.160 \mathrm{~s}$. b HPLC chromatogram of MHN shown retention time $4.362 \mathrm{~s}$. c LCMS peaks of MHN extract a

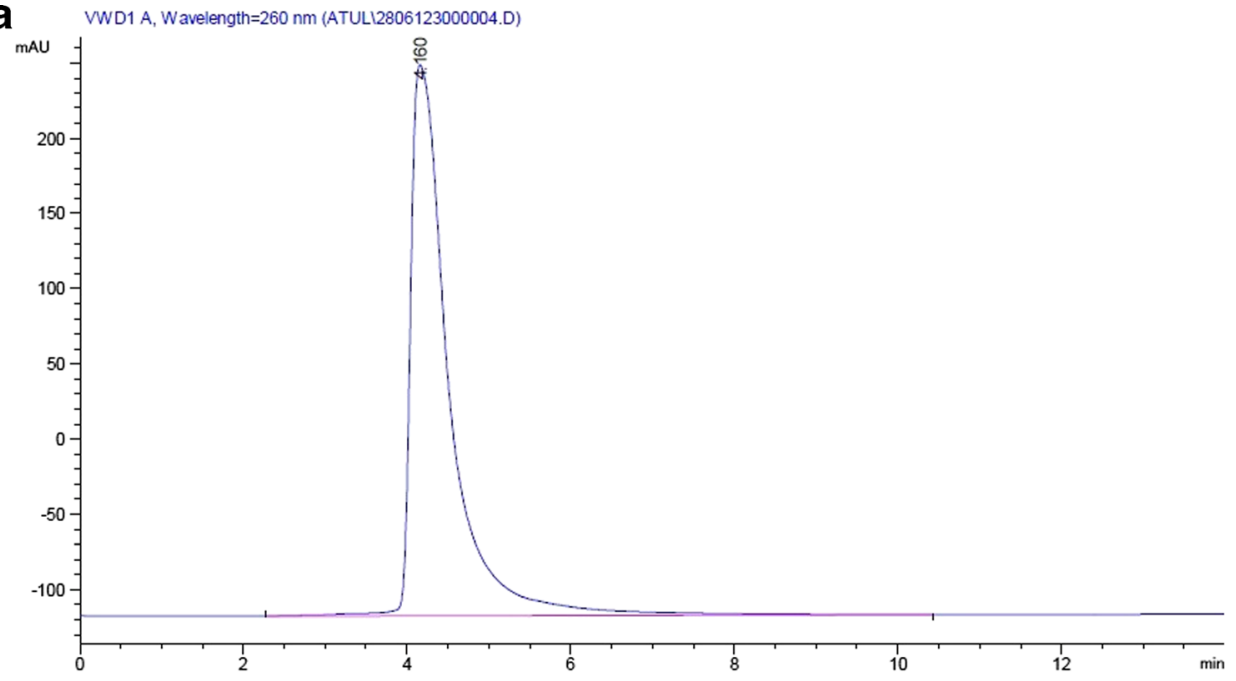

b

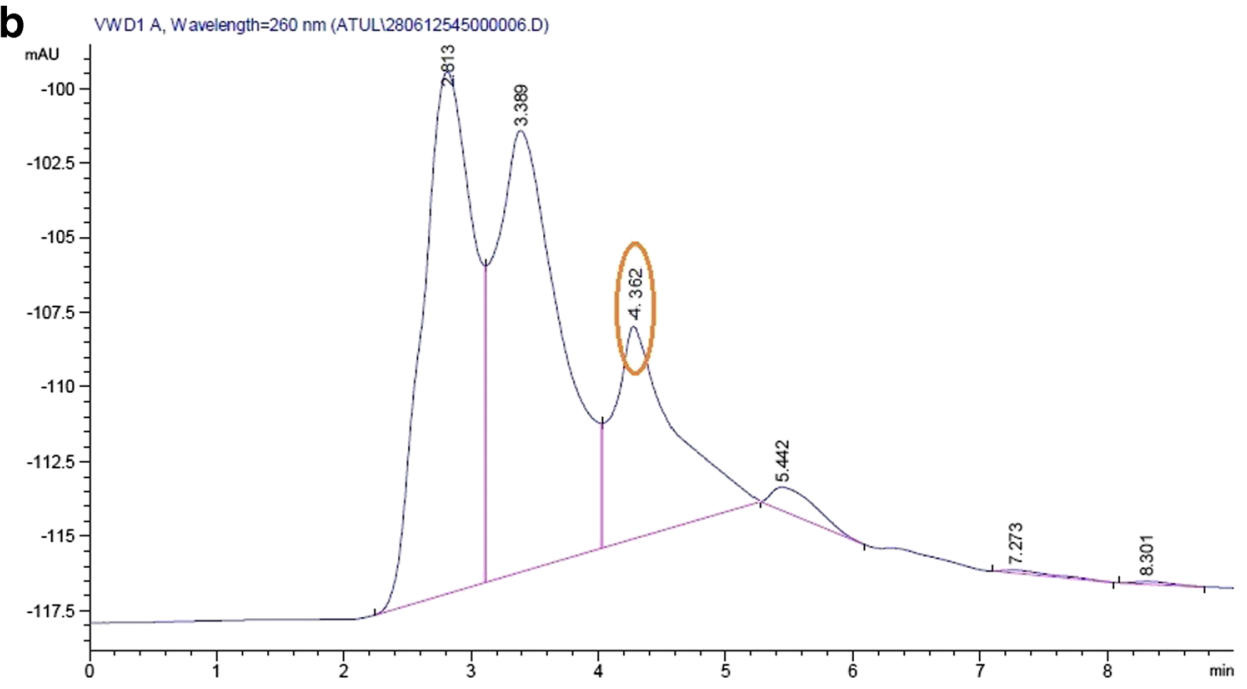

C

ext1LCMS \#151-153 RT: 4.94-5.01 AV: 2 NL: 1.87E7

F: + c ESI Full ms [ $90.00-800.00]$

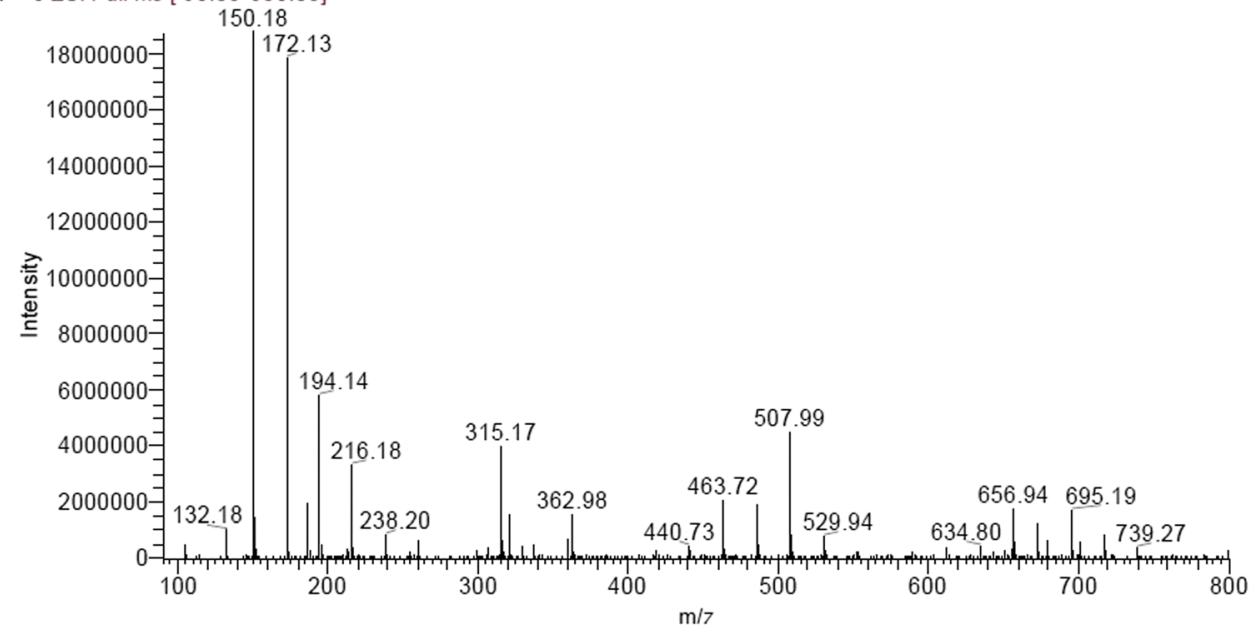

